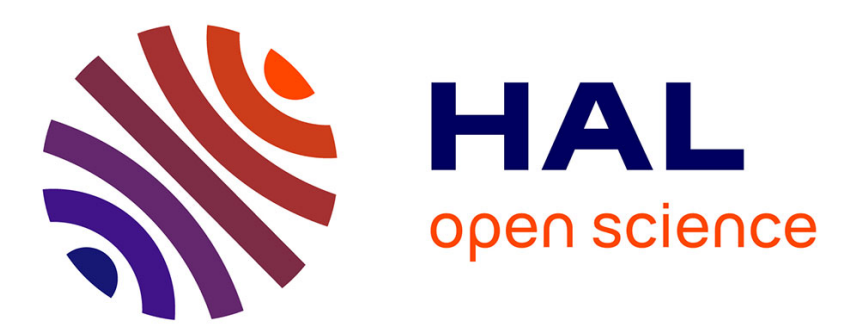

\title{
Effect of simulated foregut digestion on the antioxidant capacity of plants naturally consumed by horses
}

\author{
Zélie Triaux, Léa Briard, Odile Petit, Eric Marchioni, Diane Julien-David
}

\section{To cite this version:}

Zélie Triaux, Léa Briard, Odile Petit, Eric Marchioni, Diane Julien-David. Effect of simulated foregut digestion on the antioxidant capacity of plants naturally consumed by horses. Animal Feed Science and Technology, 2021, 282, pp.1-7. 10.1016/j.anifeedsci.2021.115121 . hal-03433099

\section{HAL Id: hal-03433099 \\ https://hal.science/hal-03433099}

Submitted on 26 Nov 2021

HAL is a multi-disciplinary open access archive for the deposit and dissemination of scientific research documents, whether they are published or not. The documents may come from teaching and research institutions in France or abroad, or from public or private research centers.
L'archive ouverte pluridisciplinaire HAL, est destinée au dépôt et à la diffusion de documents scientifiques de niveau recherche, publiés ou non, émanant des établissements d'enseignement et de recherche français ou étrangers, des laboratoires publics ou privés. 
2 Effect of simulated foregut digestion on the antioxidant capacity of

4 Zélie Triaux ${ }^{1}$, Léa Briard ${ }^{2}$, Odile Petit $^{3}$, Eric Marchioni ${ }^{1}$, Diane Julien-David ${ }^{1 *}$

${ }^{1}$ Université de Strasbourg, CNRS, IPHC UMR 7178, F-67000 Strasbourg, France

${ }^{2}$ Université Paul Sabatier, CNRS, Research Center on Animal Cognition UMR 5169,

8 Toulouse, France

$9 \quad{ }^{3}$ Université de Tours, CNRS, INRAe, IFCE, UMR 7247, Nouzilly, France

* Corresponding author: Diane Julien-David: diane.julien-david@unistra.fr ; +33 36885 4160

\section{Abstract}

Herbal medicine has impacted veterinary medicine including equine practice. Many of the postulated health-promoting effects of medicinal plants are discussed in the context of their antioxidative properties, but different factors such as digestion can have an effect on the activities of compounds. The effect of simulated foregut digestion conditions on the antioxidant capacity of seven different plants commonly consumed by horses and/or present in their complementary diet was investigated. Plants included willow tree (Salix cinerea), purple willow (Salix purpurea), willow regrowth (new sprouts growing at the foot of willows (Salix cinerea), oak tree (Quercus spp.), meadowsweet (Filipendula ulmaria spp.), hawthorn 
(Crataegus), and blackthorn (Prunus spinosa). Aqueous extracts obtained from the bark and from the leaves were compared. Two methods, Oxygen Radical Absorbance Capacity (ORAC) and Trolox equivalent antioxidant capacity (TEAC) using 2,2-azinobis-(3ethylbenzothiazoline-6-sulfonic acid) (ABTS) radical scavenging assays, were used to measure the total antioxidant capacity (TAC) of the extracts before and after the digestion process. The results showed that the TAC of all studied plant extracts decreased $(\mathrm{P}<0.05)$ following the digestion process indicating that the active compounds present in the extracts were degraded. In fact, a decrease in TAC values of up to $80 \%$ and $83 \%$ was observed using TEAC and ORAC assays respectively. Such a drop in the TAC must be taken into account when considering the antioxidative efficiency of plants consumed by animals.

Keywords: TEAC Trolox equivalent antioxidant capacity using 2,2-azinobis-(3ethylbenzothiazoline-6- sulfonic acid) (ABTS), ORAC oxygen radical absorbance capacity, herbal extract, equine.

\section{Abbreviations:}

AAPH, 2,2'-azobis-(2-methylpropionamidine) dihydrochloride

ABTS, 2,2-azinobis-(3-ethylbenzothiazoline-6-sulfonic acid)

ASE, accelerated solvent extraction system

DMSO, dimethyl sulfoxide

$\mathrm{HCl}$, chloridic acid

$\mathrm{KCl}$, potassium chloride

$\mathrm{K}_{2} \mathrm{~S}_{2} \mathrm{O}_{8}$, potassium persulfate

$\mathrm{KH}_{2} \mathrm{PO}_{4}$, potassium phosphate

$\mathrm{Na}_{2} \mathrm{HPO}_{4} \cdot 2 \mathrm{H}_{2} \mathrm{O}$, di-sodium hydrogen phosphate dihydrate 
$\mathrm{NaCl}$, sodium chloride

$\mathrm{NaOH}$, sodium hydroxide

ORAC, oxygen radical absorbance capacity

PBS, phosphate buffer saline

TAC, total antioxidant capacity

TEAC, trolox equivalent antioxidant capacity

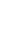

\section{Introduction}

Plant-based recipes have been traditionally used for their potential health promoting properties since ancient times, but they have gained increased interest over the past two decades. As a consequence, the global phytotherapy and homeopathy market value has increased from \$19.4 billion in 1999 to $\$ 83$ billion in 2008 (Robinson and Zhang, 2011). The use of medicinal plants is impacting not only human but also veterinary medicine, with herbal treatments being increasingly used for animal performance improvement or as alternative therapies for injuries or diseases. It is a traditional practice for horse owners, breeders or trainers to use various plant extracts for therapeutic applications or feed additives (Elghandour et al., 2018). With regard to equine diet, willow (Salix) bark is used as feed supplement to treat joint and metabolic problems, and ginseng, which is one of the most commonly used supplements, is used to reduce stress, improve performance and stimulate the immune system (Williams and Lamprecht, 2008). However some plant species such as St. John's wort (Hypericum perforatum), mistle-toe (Phoradendron flavescens), black cherry (Prunus serotine), and castor bean (Ricinus communis) are considered to be toxic for equines (Lans et al., 2006).

The health-promoting effects of plant extracts are often attributed to their antioxidative properties. These extracts are in fact known to possess potent antioxidant properties mainly 
due to the presence of phenolic compounds. Such antioxidant compounds have been identified in plant extracts used as feed additives in horse nutrition (Elghandour et al., 2018; Williams and Lamprecht, 2008). Diet supplementation with such compounds can reduce the risk of developing diseases related to oxidative stress. Siard et al. suggested that polyphenols can be used to combat chronic inflammation in horses (Siard et al., 2016). In fact, they are known to quench the proliferation of radical oxygen and reactive nitrogen species which are implicated in etiology of different diseases such as cancer, obesity, coronary heart diseases, diabetes, asthma and rhinitis in humans (Barnham et al., 2004; Eberhardt et al., 2000; Finkel and Holbrook, 2000).

Chemical and biochemical assays exist that can be used to quantify the Total Antioxidant Capacity (TAC) of plant extracts. These assays involve reactions with either a single electron transfer or a hydrogen atom transfer (Huang et al., 2005). Yet, a major drawback of these assays is the lack of information on the bioavailability of the bioactive molecules following the digestion process for instance (Stahl et al., 2002). In vitro studies have shown that some individual antioxidants may remain stable and active throughout the human digestion (Ryan et al., 2008; Wootton-Beard et al., 2011). Such data is lacking when it comes to the equine digestion system which is quite different from the human one.

The aim of this study was to evaluate the stability of the antioxidant capacity of different plants commonly consumed by horses and/or used in their complementary diet after a simulated in vitro horse digestion. The TAC was evaluated using the oxygen radical absorbance capacity (ORAC) and Trolox equivalent antioxidant capacity (TEAC) using 2,2azinobis-(3-ethylbenzothiazoline-6-sulfonic acid) (ABTS) radical scavenging assays.

\section{Materials and methods}

\subsection{Reagents}


All solvents used in this study were of analytical grade. Ethanol, dimethyl sulfoxide (DMSO), 2,2'-azino-bis-(3-ethylbenthioazoline-6-sulfonic acid) (ABTS), 3H-xanthene-3-one (fluorescein), 2,2'-azobis-(2-methylpropionamidine) dihydrochloride (AAPH), and 6hydroxy-2,5,7,8-tetramethylchromane-2-carboxylic acid (Trolox) were purchased from Sigma-Aldrich (Steinheim, Germany). Chloridic acid $(\mathrm{HCl})$, sodium hydroxide $(\mathrm{NaOH})$ and sodium chloride $(\mathrm{NaCl})$ were obtained from Thermo Fisher Scientific (Illkirch-Graffenstaden, France). Porcine pepsin (500 U/g USP) was purchased from VWR (Fontenay-sous-bois, France). Porcine pancreatin (25 $000 \mathrm{U} / g$ USP), potassium persulfate $\left(\mathrm{K}_{2} \mathrm{~S}_{2} \mathrm{O}_{8}\right)$ and potassium chloride $(\mathrm{KCl})$ were obtained from Alfa Aesar (Kandel, Germany). Di-sodium hydrogen phosphate dihydrate $\left(\mathrm{Na}_{2} \mathrm{HPO}_{4} \cdot 2 \mathrm{H}_{2} \mathrm{O}\right)$ and potassium phosphate $\left(\mathrm{KH}_{2} \mathrm{PO}_{4}\right)$ were purchased from Merck (Molsheim, France). Milli-Q water (18.2 M 2 ) was generated by Millipore synergy system (Molsheim, France).

\subsection{Plants}

Plants were selected based on their spontaneous consumption by semi-free ranging domestic horses (group 1, $\mathrm{n}=13$, pasture $=17$ ha, Louhans, France; group 2, $\mathrm{n}=7$, pasture $=10$ ha, Hauteville-Lompnes, France). Plant consumption was based on behavioral observation conducted 6 hours per day, 6 days a week over a period of 3 months. Behavioral observations were made by two observers on foot that maintained a minimum distance of 50 meters with horses. Observations were recorded using a videocamera and/or a voice recorder. Observers recorded any feeding event that was not grass grazing by stating the start and end time as well as the number of bites. In the case of tree browsing, observers counted the number of branches that were eaten while also indicating their approximate length and whether leaves 
were present. Plant species identification was first made at a distance and was later confirmed by the observer once the feeding event was over and the focal horse had moved away.

During the period of observation, horses did not receive any supplemental hay. Nearby rivers provided an ad libitum access to fresh water. In total the leaves and barks of 7 different plants were manually collected: willow tree (Salix cinerea), purple willow (Salix purpurea), willow regrowth (new sprouts growing at the foot of willows), oak tree (Quercus spp.), meadowsweet (Filipendula ulmaria), hawthorn (Crataegus spp.) and blackthorn (Prunus spinosa). For each plant species, samples were taken from 7 different specimens that were spread all over the pasture and at least 30 meters apart. A total of $700 \mathrm{~g}$ of plant material was collected for each specimen (total 7 x $700 \mathrm{~g}=4900 \mathrm{~g}$ for each plant species). Plant samples were stored at $20^{\circ} \mathrm{C}$ within 2 hours of collection and then cryogenically grounded with a grid of $1 \mathrm{~mm}$ in diameter in order to obtain a fine powder which was then stored at room temperature in sealed bags protected from the light.

\subsection{Simulated foregut digestion}

The simulated foregut horse digestion was adapted from Abdouli and Attia (2007). The used protocol simulated the digestion of feed in the stomach and small intestine of the horse. First, a pepsin aqueous solution at $10 \mathrm{~g} / \mathrm{L}$ was prepared in $0.1 \mathrm{~mol} / \mathrm{L} \mathrm{HCl}$ at a final $\mathrm{pH}$ of 2.0. Then, $1 \mathrm{~g}$ of finely ground dry plant was added to $20 \mathrm{~mL}$ of the previously prepared pepsin solution. This mixture was incubated at $39{ }^{\circ} \mathrm{C}$ in a temperature-controlled oven under agitation for 2 hours. This first step simulated the digestion in the horse stomach. After the required incubation time had elapsed, $12 \mathrm{~mL}$ of a solution of $\mathrm{NaOH}$ at $0.2 \mathrm{~mol} / \mathrm{L}$ was added to the previous mixture to obtain a $\mathrm{pH}$ of 7 . Then, $13 \mathrm{~mL}$ of an aqueous pancreatin solution at 10 $\mathrm{g} / \mathrm{L}$ were added. The resulting mixture was incubated at $39{ }^{\circ} \mathrm{C}$ under agitation for additional 4 hours. In those conditions, the digestion in the horse small intestine was simulated as 
pancreatin was a mixture of amylase and lipase, two necessary enzymes for this digestion.

145 Finally, to neutralize the enzymes activity, the mixture was placed at $100{ }^{\circ} \mathrm{C}$ for $3 \mathrm{~min}$. The 146 mixture was then placed at $-80{ }^{\circ} \mathrm{C}$ overnight and lyophilized (Labconco FreeZone, Fisher

147 Scientific, Illkirch, France) for about 48 hours until a dry powder was obtained.

Plant extracts were obtained by solid-liquid extraction under pressure using an ASE-350 Accelerated Solvent Extraction system (Dionex, Sunnyvale, CA, USA). For each plant, three extracts were done for the leaves and three extracts for the bark. The extraction solvent was a $50 / 50 \%(\mathrm{v} / \mathrm{v})$ mixture of water and ethanol. For the extraction, $1 \mathrm{~g}$ of finely grounded plant powder or $1 \mathrm{~g}$ of plant which was subjected to the simulated foregut digestion mixed with chemically inert Fontainebleau sand (previously heated at $600{ }^{\circ} \mathrm{C}$ for 4 hours) were placed into a 10-mL stainless steel extraction cell. Two $27 \mathrm{~mm}$ cellulose filters (Dionex, Sunnyvale, CA, USA) were placed at the bottom and at the top of the extraction cell. The extraction cell was then subjected to three cycles of extraction at $40{ }^{\circ} \mathrm{C}$ and 100 bars. The duration of one cycle was $10 \mathrm{~min}$. The whole extraction process took $30 \mathrm{~min}$. After extraction, the solvent was evaporated under a gentle nitrogen flow. The extracts were weighed and kept at $4{ }^{\circ} \mathrm{C}$ in amber vials to protect the molecules from light degradation.

162 To evaluate the antioxidant capacity, the extracts were dissolved at a concentration of $1 \mathrm{mg} / \mathrm{mL}$ in DMSO prior to the different assays carried out. 
For both TEAC and ORAC assays, trolox was used as a standard for quantitative assessment of the antioxidant activity and calibration curves were done using a range of concentration from 50 to $500 \mu \mathrm{mol} / \mathrm{L}$ and were prepared in Milli-Q water (Molsheim, France)..

\subsubsection{TEAC}

The principle of the antioxidant capacity evaluation by the TEAC assay is based on the electron loss of the cationic radical $\mathrm{ABTS}^{+}$. Indeed, during this reduction by an antioxidant, $\mathrm{ABTS}^{++}$, initially colored blue-green, becomes colorless. The measured absorbance can then be directly and quantitatively linked to the total antioxidant capacity of the extracts. The radical cation $\mathrm{ABTS}^{++}$was formed by adding a solution of potassium persulfate at $2.5 \mathrm{mmol} / \mathrm{L}$ to a solution of ABTS at $7.5 \mathrm{mmol} / \mathrm{L}$. The solution was left overnight at $4{ }^{\circ} \mathrm{C}$ protected from

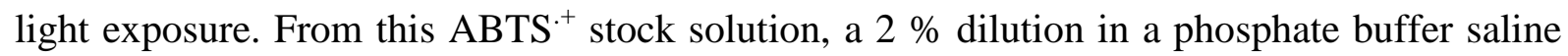
(PBS) was obtained. The PBS was prepared by dissolving $8.2 \mathrm{~g}$ of $\mathrm{NaCl}, 1.4 \mathrm{~g}$ of $\mathrm{Na}_{2} \mathrm{HPO}_{4}$, $0.27 \mathrm{~g}$ of $\mathrm{KH}_{2} \mathrm{PO}_{4}$ and $0.15 \mathrm{~g}$ of $\mathrm{KCl}$ in $1 \mathrm{~L}$ of Milli-Q water. The TEAC assay was conducted on a 96-wells microplate (Thermo Fisher scientific, Newport, United Kingdom) in which 10 $\mu \mathrm{L}$ of each extract and $200 \mu \mathrm{L}$ of the $2 \% \mathrm{ABTS}^{+}$solution were added in each well. To promote redox reactions between the $\mathrm{ABTS}^{+}$and the molecules in the extracts, the microplate was placed at $37{ }^{\circ} \mathrm{C}$ for $10 \mathrm{~min}$. Finally, the absorbance at $734 \mathrm{~nm}$ was read in each well by a Varioskan spectrophotometer (Thermo Fisher Scientific, Illkirch-Graffenstaden, France).

Prior to the absorbance measurement, the plate was agitated for 10 seconds. The extracts with an antioxidant capacity were then identified by a decrease in intensity as the radical cation ABTS $^{++}$would have lost its blue-green color. The TAC values of each extract were measured in triplicate.

The loss of TAC in plant extracts after simulated foregut digestion was calculated as follows: (TAC value of non-digested plant extract - TAC value of digested plant extract)/(TAC value of non-digested plant extract) and multiplied with 100 for reporting the loss in percent. 
193

The ORAC assay is based on a competition between a fluorescent probe and the antioxidant compounds present in the extract. The fluorescent probe used in this study was the 3H-xanthen-3-one, also known as fluorescein. This compound is degradable by oxidation reactions by a transfer of protons, leading to the extinction of its fluorescence. AAPH $(2,2$ 'azobis-(2-methylpropionamidine)) was used as the initiator of the oxidation reactions as it dissociates at $27{ }^{\circ} \mathrm{C}$ by releasing peroxylic radicals. Antioxidant molecules present in the analyzed extract will absorb the free radicals generated by AAPH, the fluorescein will be protected and there will be a delay in the decrease of the fluorescence. The TAC of the extract is thus directly linked to the decreasing curve of the measured fluorescence delay. To quantify the TAC, the area under the fluorescence curve of the studied extracts is calculated.

The ORAC assay was conducted on a 96-wells dark microplate (Thermo Fisher scientific, Newport, United Kingdom), to prevent the degradation of the fluorescein by light. In each well, $10 \mu \mathrm{L}$ of the extract and $150 \mu \mathrm{L}$ of a solution of fluorescein at $2.8 \times 10^{-5} \mathrm{~g} / \mathrm{L}$ in MilliQ water were added. The microplate was then placed in a fluorescence microplate reader (Varioskan, Thermo Fisher Scientific, Illkirch-Graffenstaden, France), shaken for $20 \mathrm{sec}$ and incubated at $37{ }^{\circ} \mathrm{C}$ for $15 \mathrm{~min}$. Then, using an automatic dispenser integrated into the fluorescence reader, $30 \mu \mathrm{L}$ of an AAPH solution in PBS at $41.5 \mathrm{~g} / \mathrm{L}$ were added to each well. The microplate was agitated again for $5 \mathrm{sec}$. The fluorescence kinetics was then measured every $5 \mathrm{~min}$ for 2 hours with excitation and emission wavelengths of $485 \mathrm{~nm}$ and $530 \mathrm{~nm}$ respectively. The experiments for each extract were conducted in triplicate.

The percentage loss of TAC of extract plant non digested and digested was calculated as TEAC assay. 


\subsection{Statistical analysis}

217

The means of triplicate TAC values (experimental unit) for each plant extract obtained with TEAC or ORAC assays were compared before and after simulated digestion, the paired, twotailed $t$ test was used using the software Minitab (2017) v.17. Means with P value $<0.05$ were considered statistically different.

\section{Results}

In this study, two methods, TEAC and ORAC, were used to evaluate the TAC of seven selected plant extracts before and after a simulated foregut digestion. The concerned plants were willow tree, oak tree, purple willow, willow regrowth, meadowsweet, hawthorn, and blackthorn. Aqueous extracts from the leaves and from the bark of willow tree, oak tree, purple willow and willow regrowth were used. For the three remaining plants, only aqueous leaf extracts were used, either because they don't have a bark (meadowsweet) or because their bark is not consumed by horses due to the presence of large thorns (hawthorn and blackthorn).

Figure 1 shows the TAC expressed in $\mu$ mol Trolox equivalent per gram of plant $(\mu$ mol $\mathrm{TE} / \mathrm{g}$ of plant) of each plant extract before and after simulated foregut digestion for TEAC (figure 1.A) and ORAC (figure 1.B) methods.

\subsection{TEAC assay}

Prior to simulated foregut digestion, the TAC of all plant extracts assessed using TEAC assay showed a level of antioxidant activity with values ranging from 1538 to $10119 \mu \mathrm{mol} \mathrm{TE} / \mathrm{g}$ of plant extract. The lowest TAC value was obtained with the extract of purple willow leaves and the highest with the extract of oak tree bark. 
Among bark extracts, the lowest TAC value was observed with the extract of purple

willow ( $3778 \pm 387 \mu \mathrm{mol} \mathrm{TE} / \mathrm{g}$ of plant) while the highest value was obtained with the oak tree extract (10 $119 \pm 1748 \mu \mathrm{mol} \mathrm{TE} / \mathrm{g}$ of plant). Among leaf extracts, purple willow extract (1 $538 \pm 65 \mu \mathrm{mol} \mathrm{TE} / \mathrm{g}$ of plant) and oak tree extract $(7083 \pm 1256 \mu \mathrm{mol} \mathrm{TE} / \mathrm{g}$ of plant) showed the lowest and the highest TAC value using TEAC assay, respectively. The bark and leaf extracts of oak tree showed the highest TAC values compared to the other plant extracts. The bark extracts of willow tree, purple willow, willow regrowth and oak tree showed higher TAC values compared to their respective leaf extracts $(\mathrm{P}<0.05)$. This suggests that the bark may contain more antioxidants than the leaves.

After the simulated foregut digestion, the TAC values of all plant extracts decreased $(\mathrm{P}<0.05)$ (figure 1). The highest TAC value was observed with the bark extract of the willow tree $(2421 \pm 322 \mu \mathrm{mol} \mathrm{TE} / \mathrm{g}$ of plant) and the lowest value with blackthorn leaf extract (1 008 $\pm 87 \mu \mathrm{mol} \mathrm{TE} / \mathrm{g}$ of plant). Table 1 shows the percentage loss of TAC before and after digestion for each plant extract for both TEAC and ORAC assays. The loss ranged from $80 \%$ to $16 \%$ with the TEAC assay. The TAC values of the bark and leaf extracts of oak tree, which were the highest before digestion, decreased by $80 \%$ after being subjected to the simulated foregut digestion process (table 1). Moreover, the observed pattern with nondigested extracts of same plant, where the TAC values of bark were higher than those of leaves, was not observed with the digested extracts. In fact, the TAC values of bark extracts were similar or lower than those obtained with leaf extracts.

\subsection{ORAC assay}

For the ORAC assay, the TAC values obtained prior to simulated foregut digestion ranged from 2216 to $16915 \mu \mathrm{mol} \mathrm{TE} / \mathrm{g}$ of plant. 
TAC value (16 915 $\pm 1384 \mu \mathrm{mol} \mathrm{TE} / \mathrm{g}$ of plant) while its leaf extract showed the lowest value (2 $216 \pm 311 \mu \mathrm{mol}$ TE/g of plant). Among bark extracts, the lowest TAC value was observed with the extract of purple willow (3 $790 \pm 74 \mu \mathrm{mol} \mathrm{TE} / \mathrm{g}$ of plant) while the highest value was obtained with the willow tree extract (16 $915 \pm 1384 \mu$ mol TE/g of plant). Among leaf extracts, the lowest TAC value was observed with the willow tree extract (2 $216 \pm 311 \mu \mathrm{mol}$ $\mathrm{TE} / \mathrm{g}$ of plant) and the highest value with the oak tree extract (12 $426 \pm 418 \mu \mathrm{mol} \mathrm{TE} / \mathrm{g}$ of plant). As with the TEAC assay, the bark extracts of the willow tree, purple willow and willow regrowth showed higher TAC values than the respective leaf extract $(\mathrm{P}<0.05)$ (figure 1). However, this pattern was not observed with the oak tree extracts with the leaves showing higher ORAC TAC values than the bark $(\mathrm{P}<0.05)$ (figure 1).

After the simulated foregut digestion, the ORAC TAC values of all plant extracts were lower $(\mathrm{P}<0.05)$ and ranged from 932 to $5108 \mu \mathrm{mol} \mathrm{TE} / \mathrm{g}$ of plant (figure 1). According to table 1 , the decrease ranged from $83 \%$ to $20 \%$. The bark extract of the willow tree which showed the highest TAC value was reduced by $83 \%$ following simulated digestion. As with the TEAC assay, this reduction resulted in TAC values equivalent to those of leaf extracts.

\section{Discussion}

In this study, TAC of seven different plants naturally consumed by horses was measured by two different methods, TEAC and ORAC. The TEAC method measures the capacity of the compound to donate electrons, while the ORAC method measures the capacity of a molecule to transfer hydrogen atoms. The obtained TAC values with the two methods can therefore not be compared as they represent different antioxidant phenomena measured in different conditions (Schaich et al., 2015). The TAC values were between 1538 and $10119 \mu \mathrm{mol}$ 
TE/g of plant using TEAC assays. By comparison, according to Jiménez-Zamora et al. (2016), the aqueous extract of green tea leaves has a TAC of about $2289 \mu \mathrm{mol} \mathrm{TE} / \mathrm{g}$ of plant as measured by the TEAC assay. This shows that the plants studied have a high antioxidant capacity as their TAC are higher or at least close to that of green tea leaves, a plant wellknown for its antioxidant activity (Jiménez-Zamora et al., 2016). Furthermore, the TAC values measured for leaves were lower than those of the bark $(\mathrm{P}<0.05)$ (figure 1). This result shows the importance of studying different parts of the plants as differences may exist in the contents of active compounds.

The effect of simulated foregut digestion on the TAC of the seven studied plants was also investigated. The results of both TEAC and ORAC assays showed a dramatic decrease in TAC following digestion (-16\% to $-80 \%$ with TEAC and $-20 \%$ to $-83 \%$ with ORAC) (table1). To the best of our knowledge, this study is the first to investigate the influence of our model of simulated foregut horse digestion on the TAC of plants and to demonstrate the decrease of TAC values following simulated foregut digestion. As far as comparison can be made, our results are in agreement with those of other studies using simulated in vitro human digestion which showed a similar trend (Bermúdez-Soto et al., 2007; Chen et al., 2013; McDougall et al., 2005). For example, Chen et al. studied the influence of in vitro human digestion on the TAC of tea juices measured by the TEAC assay. They showed that the simulated digestion process led to a decrease of the TAC values of six tea juices out of nine (Chen et al., 2013). Bermúdez-Soto et al. (2007) showed a decrease in TAC after an in vitro pancreatic digestion of different chemical compounds found in chokeberry juice such as anthocyanins (-43\%), flavonols (-26\%) and flavan-3-ols (-19\%). In other studies based on the TEAC assay, it was observed on the other hand that some extracts can stay stable throughout the digestive process (gastric and pancreatic) such as extract Perennial chamomile 
(Chamaemelum nobile) or Japanese plum (Prunus salicina) seeds extract (Chen et al., 2015, 2016; Wootton-Beard et al., 2011).

The decrease of the TAC of the plant extracts may be due to the degradation of antioxidant compounds present in the extracts. In fact, some compounds known for their antioxidant activity, such as polyphenols - a major family of natural products found in plantsmay be decomposed into different structural forms with different chemical and biological properties during the pancreatic digestion due to their sensitivity to $\mathrm{pH}$ variations (BermúdezSoto et al., 2007). Indeed it has been shown in vitro that the $\mathrm{pH}$ influences oxidoreductions of phenolic compounds. Some phenolic compounds have for instance displayed prooxidant activities at $\mathrm{pH} 7.4$, while at lower $\mathrm{pH}$ (5.8) they were reported to possess antioxidant activities (Decker, 2009; Moran et al., 1997). Other factors such as the interactions of phenolic compounds with other food components released during digestion (iron, other minerals, dietary fiber, proteins) may influence the antioxidant properties of phenolic compounds. In fact, it has been shown that the antioxidant activity of free phenols is higher compared to iron-phenol chelates (Argyri et al., 2006; Hajji et al., 2006; Seraglio et al., 2017). In addition, the antioxidant activity of phenolic compounds also depends on their chemical structure, mainly the number and position of the hydrogen-donating hydroxyl groups on the aromatic rings (Rice-Evans et al., 1996). Previous works have also showed the degradation of anthocyanins, known antioxidant compounds, after being subjected to the alkaline conditions of the pancreatic digestion process (McDougall et al., 2005; Pérez-Vicente et al., 2002). In this study, a simulated foregut digestion with porcine enzymes was conducted. However, the results obtained with our mimetic horse foregut digestion have to be nuanced. Firstly, the conditions of the simulated foregut horse digestion, based on the work of Abdouli and Attia (2007), used a temperature lightly higher $\left(39^{\circ} \mathrm{C}\right)$ than equine body temperature which is in range of $37.5^{\circ} \mathrm{C}$ and $38^{\circ} \mathrm{C}$. Secondly incubation time used in our model was 
different than what happens during horse's digestion. Indeed food passes the stomach quickly (15 $\mathrm{min}$ ) in case of it is roughage, and more slowly if it is concentrates and ingested feed reaches the caecum within 2 hours (Jones, 1993). And finally, compared to eight other species, it appear than horses pancreatic secretions into the duodenum have low enzyme activity (Frape, 2004; Lorenzo-Figueras et al., 2007). It was showed in the study of LorenzoFigueras et al. (2007) than the specific enzyme activity of five pancreatic enzymes of swine (amylase, lipase, elastase, trypsin, chymotrypsin) was higher than for horses. The activity measurement of five pancreatic enzymes from the adult equine and porcine pancreas was reported by Sweeney (2012), expressed as mean units per milligram of DNA: for amylase, the activity was 2.3 and 107 for equine and porcine respectively, for lipase 41.5 and 49 , elastase 0.07 and 0.22 , trypsin 0.13 and 0.44 and for chymotrypsin 0.36 and 2.26 . Thus, considering these different points, in our study the impact of the enzymes on the TAC values is higher than expected in vivo. In vivo animal studies will have to come in support of the obtained in vitro data.

\section{Conclusion}

This study shows that despites the negative impact of the digestion on their antioxidant activities, the studied plants remain a source of antioxidant compounds. Despite the acknowledged limitations of in vitro models that try to mimic in vivo conditions, they remain a useful tool to investigate enzymatic activity and its effect on biological activities of antioxidants. It would be important to investigate in detail the outcome of the bioactive compounds after the digestion by identifying their degradation products and the subsequent impact on their bioavailability and biological activity.

\section{Acknowledgments}


l'Equitation, Saumur, France).

\section{References}

Abdouli, H., Attia, S.B., 2007. Evaluation of a two-stage in vitro technique for estimating digestibility of equine feeds using horse faeces as the source of microbial inoculum. Anim. Feed Sci. Technol. 132, 155-162. https://doi.org/10.1016/j.anifeedsci.2006.03.005

Argyri, K., Komaitis, M., Kapsokefalou, M., 2006. Iron decreases the antioxidant capacity of red wine under conditions of in vitro digestion. Food Chem. 96, 281-289. https://doi.org/10.1016/j.foodchem.2005.02.035

Barnham, K.J., Masters, C.L., Bush, A.I., 2004. Neurodegenerative diseases and oxidative stress. Nat. Rev. Drug Discov. 3, 205. https://doi.org/10.1038/nrd1330

Bermúdez-Soto, M.-J., Tomás-Barberán, F.-A., García-Conesa, M.-T., 2007. Stability of polyphenols in chokeberry (Aronia melanocarpa) subjected to in vitro gastric and pancreatic digestion. Food Chem. 102, 865-874. https://doi.org/10.1016/j.foodchem.2006.06.025

Chen, G.-L., Chen, S.-G., Chen, F., Xie, Y.-Q., Han, M.-D., Luo, C.-X., Zhao, Y.-Y., Gao, Y.-Q., 2016. Nutraceutical potential and antioxidant benefits of selected fruit seeds subjected to an in vitro digestion. J. Funct. Foods 20, 317-331. https://doi.org/10.1016/j.jff.2015.11.003

Chen, G.-L., Chen, S.-G., Xie, Y.-Q., Chen, F., Zhao, Y.-Y., Luo, C.-X., Gao, Y.-Q., 2015. Total phenolic, flavonoid and antioxidant activity of 23 edible flowers subjected to in vitro digestion. J. Funct. Foods 17, 243-259. https://doi.org/10.1016/j.jff.2015.05.028

Chen, G.-L., Hu, K., Zhong, N.-J., Guo, J., Gong, Y.-S., Deng, X.-T., Huang, Y.-S., Chu, D.-K., Gao, Y.-Q., 2013. Antioxidant capacities and total polyphenol content of nine commercially available tea juices measured by an in vitro digestion model. Eur. Food Res. Technol. 236, 303-310. https://doi.org/10.1007/s00217-012-1897-2

Decker, A., 2009. Phenolics: prooxidants or antioxidants? Nutr. Rev. 55, 396-398. https://doi.org/10.1111/j.1753-4887.1997.tb01580.x

Eberhardt, M.V., Lee, C.Y., Liu, R.H., 2000. Antioxidant activity of fresh apples. Nature 405, 903. https://doi.org/10.1038/35016151

Elghandour, M.M.M.Y., Kanth Reddy, P.R., Salem, A.Z.M., Ranga Reddy, P.P., Hyder, I., BarbabosaPliego, A., Yasaswini, D., 2018. Plant bioactives and extracts as feed additives in horse nutrition. J. Equine Vet. Sci. 69, 66-77. https://doi.org/10.1016/j.jevs.2018.06.004

Finkel, T., Holbrook, N.J., 2000. Oxidants, oxidative stress and the biology of ageing. Nature 408, 239. https://doi.org/10.1038/35041687

Frape, D., 2004. Equine nutrition and Feeding. Blackwell Publishing Ltd, Oxford, UK.

Hajji, H.E., Nkhili, E., Tomao, V., Dangles, O., 2006. Interactions of quercetin with iron and copper ions: complexation and autoxidation. Free Radic. Res. 40, 303-320. https://doi.org/10.1080/10715760500484351

Huang, D., Ou, B., Prior, R.L., 2005. The chemistry behind antioxidant capacity assays. J. Agric. Food Chem. 53, 1841-1856. https://doi.org/10.1021/jf030723c

Jiménez-Zamora, A., Delgado-Andrade, C., Rufián-Henares, J.A., 2016. Antioxidant capacity, total phenols and color profile during the storage of selected plants used for infusion. Food Chem. 199, 339-346. https://doi.org/10.1016/j.foodchem.2015.12.019

Jones, S.M., 1993. Digestive System of the Horse and Feeding Management. Agric. Nat. Resour. FSA3038, 1-6.

Lans, C., Turner, N., Brauer, G., Lourenco, G., Georges, K., 2006. Ethnoveterinary medicines used for horses in Trinidad and in British Columbia, Canada. J. Ethnobiol. Ethnomedicine 2-31. https://doi.org/10.1186/1746-4269-2-31 
Lorenzo-Figueras, M., Morisset, S.M., Morisset, J., Lainé, J., Merritt, A.M., 2007. Digestive enzyme concentrations and activities in healthy pancreatic tissue of horses. Am. J. Vet. Res. 68, 10701072. https://doi.org/10.2460/ajvr.68.10.1070

McDougall, G.J., Fyffe, S., Dobson, P., Stewart, D., 2005. Anthocyanins from red wine - Their stability under simulated gastrointestinal digestion. Phytochemistry 66, 2540-2548. https://doi.org/10.1016/j.phytochem.2005.09.003

Minekus, M., Alminger, M., Alvito, P., Ballance, S., Bohn, T., Bourlieu, C., Carrière, F., Boutrou, R., Corredig, M., Dupont, D., Dufour, C., Egger, L., Golding, M., Karakaya, S., Kirkhus, B., Le Feunteun, S., Lesmes, U., Macierzanka, A., Mackie, A., Marze, S., McClements, D.J., Ménard, O., Recio, I., Santos, C.N., Singh, R.P., Vegarud, G.E., Wickham, M.S.J., Weitschies, W., Brodkorb, A., 2014. A standardised static in vitro digestion method suitable for food - an international consensus. Food Funct 5, 1113-1124. https://doi.org/10.1039/C3FO60702J

Minitab, 2017. Minitab v.17 Minitab Inc., State College, PA., USA.

Moran, J.F., Klucas, R.V., Grayer, R.J., Abian, J., Becana, M., 1997. Complexes of iron with phenolic compounds from soybean nodules and other legume tissues: prooxidant and antioxidant properties. Free Radic. Biol. Med. 22, 861-870. https://doi.org/10.1016/S08915849(96)00426-1

Pérez-Vicente, A., Gil-Izquierdo, A., García-Viguera, C., 2002. In vitro gastrointestinal digestion study of pomegranate juice phenolic compounds, anthocyanins, and vitamin C. J. Agric. Food Chem. 50, 2308-2312. https://doi.org/10.1021/jf0113833

Rice-Evans, C.A., Miller, N.J., Paganga, G., 1996. Structure-antioxidant activity relationships of flavonoids and phenolic acids. Free Radic. Biol. Med. 20, 933-956. https://doi.org/10.1016/0891-5849(95)02227-9

Robinson, M.M., Zhang, X., 2011. The World Medicines Situation 2011; Traditional medicines: global situation, issues and challenges ». Geneva: World Health Organization, Switzerland.

Ryan, L., O'Connell, O., O'Sullivan, L., Aherne, S.A., O'Brien, N.M., 2008. Micellarisation of carotenoids from raw and cooked vegetables. Plant Foods Hum. Nutr. 63, 127-133. https://doi.org/10.1007/s11130-008-0081-0

Schaich, K.M., Tian, X., Xie, J., 2015.Hurdles and pitfalls in measuring antioxidant efficacy: A critical evaluation of ABTS, DPPH, and ORAC assays. J. Funct. Foods, Natural Antioxidants 18, 782-796. https://doi.org/10.1016/j.jff.2015.05.024

Seraglio, S.K.T., Valese, A.C., Daguer, H., Bergamo, G., Azevedo, M.S., Nehring, P., Gonzaga, L.V., Fett, R., Costa, A.C.O., 2017. Effect of in vitro gastrointestinal digestion on the bioaccessibility of phenolic compounds, minerals, and antioxidant capacity of mimosa scabrella bentham honeydew honeys. Food Res. Int. 99, 670-678. https://doi.org/10.1016/j.foodres.2017.06.024

Siard, M.H., McMurry, K.E., Adams, A.A., 2016. Effects of polyphenols including curcuminoids, resveratrol, quercetin, pterostilbene, and hydroxypterostilbene on lymphocyte proinflammatory cytokine production of senior horses in vitro. Vet. Immunol. Immunopathol. 173, 50-59. https://doi.org/10.1016/j.vetimm.2016.04.001

Stahl, W., van den Berg, H., Arthur, J., Bast, A., Dainty, J., Faulks, R.M., Gärtner, C., Haenen, G., Hollman, P., Holst, B., Kelly, F.J., Cristina Polidori, M., Rice-Evans, C., Southon, S., van Vliet, T., Viña-Ribes, J., Williamson, G., Astley, S.B., 2002. Bioavailability and metabolism. Mol. Aspects Med. 23, 39-100. https://doi.org/10.1016/S0098-2997(02)00016-X

Sweeney, C.R., 2012. In vivo and in vitro digestibility of a complete pelleted feed in horses. California Polytechnic State University, San Luis Obispo, California, USA. https://doi.org/10.15368/theses.2012.167

Williams, C.A., Lamprecht, E.D., 2008. Some commonly fed herbs and other functional foods in equine nutrition: A review. Vet. J. 178, 21-31. https://doi.org/10.1016/j.tvj1.2007.06.004

Wootton-Beard, P.C., Moran, A., Ryan, L., 2011. Stability of the total antioxidant capacity and total polyphenol content of 23 commercially available vegetable juices before and after in vitro digestion measured by FRAP, DPPH, ABTS and Folin-Ciocalteu methods. Food Res. Int. 44, 217-224. https://doi.org/10.1016/j.foodres.2010.10.033 

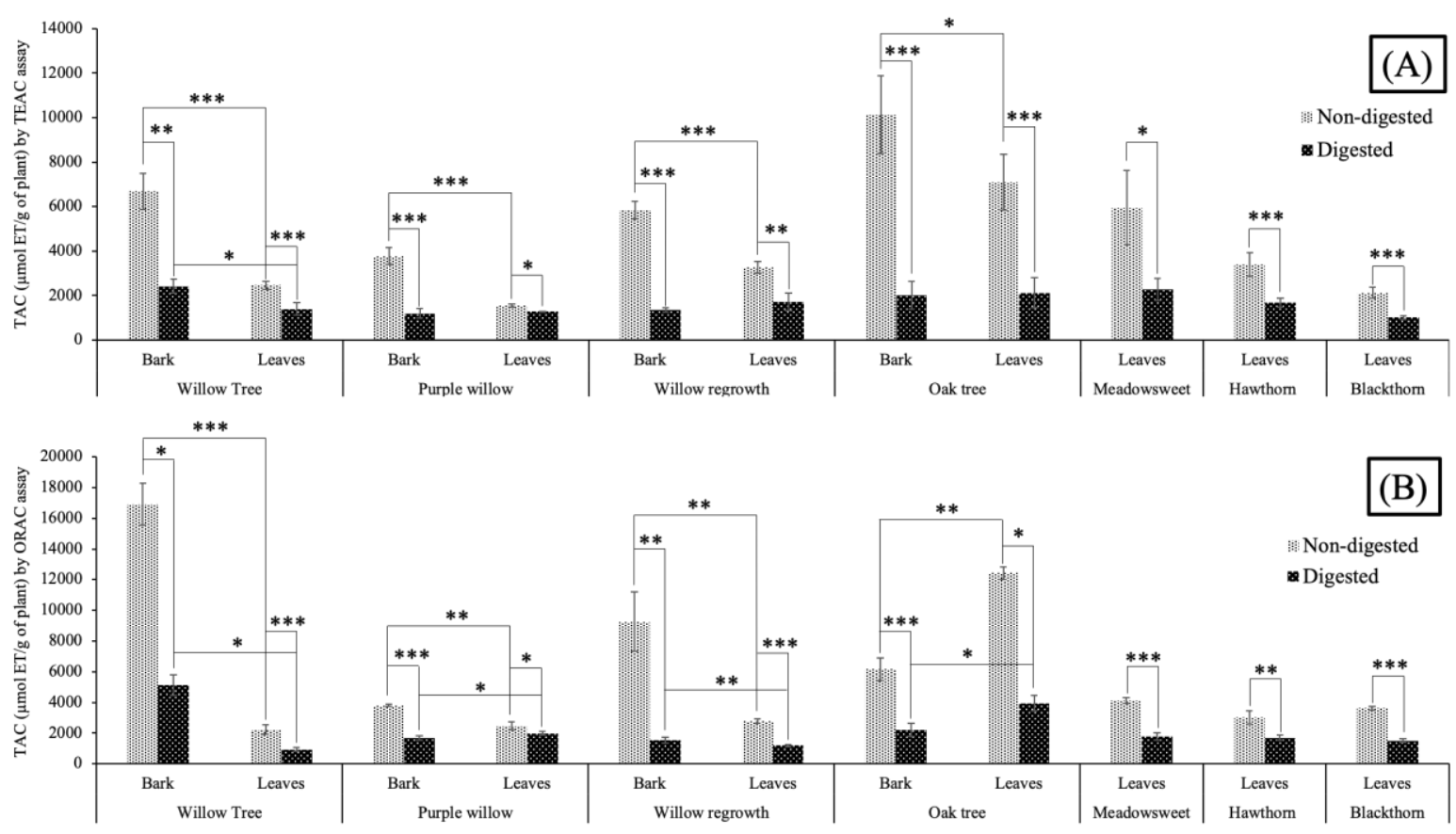

Figure 1. Total antioxidant capacity (TAC) of plant aqueous extracts before and after simulated foregut digestion obtained with TEAC (A) and ORAC (B) assays ( $n=3$, $t$-test, $\alpha=0.05, * 0.01<\mathrm{P}<0.05 ; * * 0.001<\mathrm{P}<0.01 ; * * * \mathrm{P}<0.001)$. 
471 Table 1. Loss of total antioxidant capacity (TAC) in bark, leaf and whole plant extracts after

472 simulated foregut digestion, in percent.

Plants

TAC loss (\%) TAC loss (\%)

TEAC assay

ORAC assay

\begin{tabular}{|c|c|c|c|}
\hline \multirow{2}{*}{ Willow Tree } & Bark & $64 \%$ & $70 \%$ \\
\hline & Leaves & $43 \%$ & $58 \%$ \\
\hline \multirow[b]{2}{*}{ Oak tree } & Bark & $80 \%$ & $64 \%$ \\
\hline & Leaves & $70 \%$ & $68 \%$ \\
\hline \multirow[b]{2}{*}{ Purple willow } & Bark & $68 \%$ & $55 \%$ \\
\hline & Leaves & $16 \%$ & $20 \%$ \\
\hline Willow & Bark & $77 \%$ & $83 \%$ \\
\hline regrowth & Leaves & $47 \%$ & $58 \%$ \\
\hline Meadowsweet & Whole plant & $62 \%$ & $57 \%$ \\
\hline Hawthorn & Whole plant & $51 \%$ & $44 \%$ \\
\hline Blackthorn & Whole plant & $52 \%$ & $58 \%$ \\
\hline
\end{tabular}

473

474

475 